\title{
Haploidentical Stem Cell Transplantation in Patients with Myelodysplastic Syndrome: Case Report First Experience
}

\author{
Aleksandra Pivkova-Veljanovska ${ }^{1 *}$, Irina Panovska-Stavridis ${ }^{1}$, Lazar Chadievski ${ }^{1}$, Sanja Trajkova ${ }^{1}$, Marija Popova-Labachevska ${ }^{1}$, \\ Tara Mojsovska ${ }^{1}$, Simona Stojanovska ${ }^{1}$, Nevenka Ridova ${ }^{1}$, Svetlana Krstevska-Balkanov ${ }^{1}$, Zlate Stojanoski $^{1}$, Dejan Spasovski ${ }^{2}$, \\ Radica Grubovic-Rastvorceva ${ }^{3}$, Borce Georgievski ${ }^{1}$ \\ ${ }^{1}$ University Clinic for Hematology, BMT Unit, Medical Faculty, University "St. Cyril and Methodious", Skopje, Republic of \\ Macedonia; 'University Clinic for Rheumatology, BMT Unit, Medical Faculty, University "St. Cyril and Methodious", Skopje, \\ Republic of Macedonia; ${ }^{3}$ Institute for Transfusion Medicine, Skopje, Republic of Macedonia
}

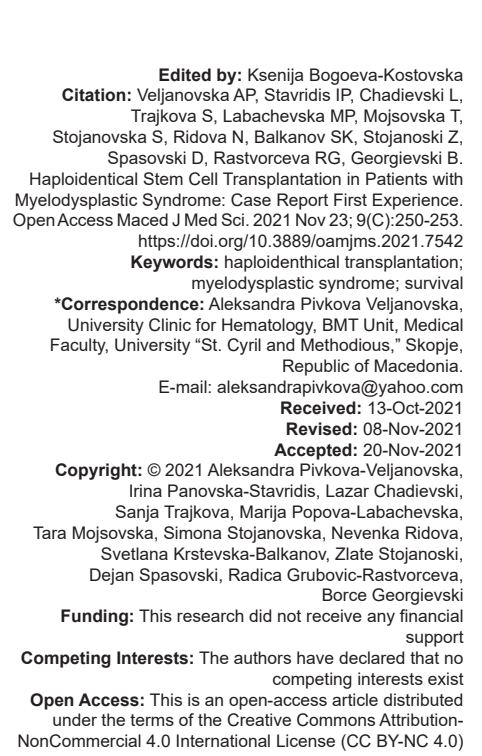

Abstract

BACKGROUND: Allogeneic stem cell transplantation is a potentially curative therapeutic approach in patients with intermediate and high-risk myelodysplastic syndrome (MDS). If a family sibling or unrelated donor is not available mismatched donors are viable option for young patients with no comorbidities.

AIM: The aim of this case presentation was to evaluate our first experience with haploidentical transplantation for this indication

CASE PRESENTATION: We present a case of 50 years male patient with MDS diagnosed at University Clinic fo hematology, Skopje, Republic of Macedonia. The patient was scored in revised international prognostic scoring system as high risk patient. He was referred for human leukocyte antigen DNA typing of family siblings and since he didn't have identical sibling and unrelated donor, he was referred to continue treatment with haploidentical stem cell transplantation. He received Flu Bu conditioning and posttransplant cyclophosphamide, cyclosporine and mycophenolate mofetil for graft-versus-host disease prophylaxis. Peripheral blood stem cells from his mismatched brother were infused in the amount of CD34 $=5.8 \times 10^{6} / \mathrm{kg}$. He experienced prolonged engraftment, severe infective bacterial infections, and cytomegalovirus (CMV) reactivation with clinical manifestation of CMV colitis. He was successfully treated with antiviral drug and completely resolved. His bone marrow analysis showed complete remission and chimerism evaluation revealed high donor engraftment. The patient is now +34 months post-transplant in complete remission.

CONCLUSION: The use of a mismatched donor increases the risk of non-relapse mortality, but there is also evidence to suggest that a haploidentical donor is a valid choice, as general outcome appears to be at least similar to matched unrelated donors.

\section{Introduction}

Allogeneic stem cell transplantation (ASCT) is a potentially curative therapeutic approach in patients with intermediate and high-risk myelodysplastic syndrome (MDS) [1]. Less than $30 \%$ of MDS patient will have available human leukocyte antigen (HLA) DNA matched sibling donor, other $50 \%$ will have matched unrelated donor and still $20 \%$ of patients lack suitable donor and are candidates for treatment with haploidentical stem cell transplantation [1]. The results in the terms of overall survival and non-relapse mortality (NRM) with matched related and unrelated donor transplants are similar and both procedures can be considered as standard of care for this indication [2]. European group for bone marrow transplantation and acute leukemia working party in the last position statement suggested that haploidentical transplantation is a viable option for patients that are lacking sibling and matched unrelated donors (MUD) in certain clinical situations especially in the case of a need for an urgent transplant procedure [3].

A readily available haploidentical donor may be considered over initiating an unrelated donor search. The results from HLA mismatched or haploidentical related donors were disappointing in the past, but improvements have been made in the conditioning platform, using T-cell depleted graft with CD34+ megadose and myeloablative conditioning, as well as using $T$ cell repleted transplants and intensive graft versus host (GVHD) prophylaxis with posttransplant cyclophosphamide (PT-CY). The PT-CY immunosuppression showed relatively low rates of acute GVHD. Nevertheless, NRM remained high at $>40 \%$, regardless of the type of GVHD prophylaxis used, and chronic GVHD was still quite frequent, involving $\sim 30 \%$ of patients [4], [5]. The aim of this article was to present our first experience with haploidentical stem cell transplantation in the treatment of MDS. 


\section{Case Presentation}

We present a case of 50 years male patient with MDS diagnosed at University Clinic for hematology, Skopje, Republic of Macedonia during January 2018. Complete blood count at diagnosis revealed a macrocytic anemia with high mean corpuscular volume, normal cobalamin, and red blood cell folate. His initial blood count was hemoglobin $(\mathrm{Hgb}) 7,7 \mathrm{~g} / \mathrm{dL}$, white blood cell (WBC) $5.0 \times 10(9) / \mathrm{L}$, and platelet (PIt) $93 \times 10(9) / L$. Coombs testing was negative, and levels of lactate dehydrogenase, haptoglobin, and unconjugated bilirubin were normal. Autoimmune disease work up showed no coexistence of rheumatological disease. Peripheral blood smear showed dysplastic changes in all hematopoietic lineages including hypogranulation and hypersegmentation of the neutrophils and rare teardrop-shaped red cells, prompting a bone marrow evaluation. Bone marrow aspirate yielded a diagnosis of MDS, refractory anemia with excess blasts (RAEB-1; 8\% blasts) with normal karyotype. Patient was scored in revised international prognostic scoring system for MDS as high risk patient [6]. He was referred for HLA DNA typing of family siblings and since he didn't have identical sibling, unrelated donor search was prompted. He required transfusion support for symptomatic anemia and became red blood cell transfusion dependent over the next several months. He started treatment with Azacitidine $100 \mathrm{mg} / \mathrm{m}^{2} / 7$ days in a total of 4 consecutive cycles.

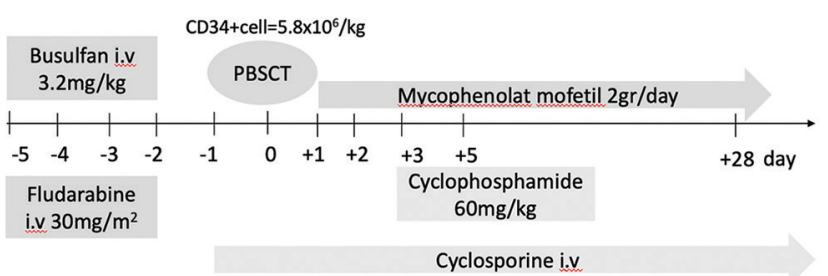

Figure 1: Conditioning regimen for haploidentical stem cell transplantation

Since the donor search in WMDA registry showed that the patient had no MUD donor he was referred to continue treatment with haploidentical stem cell transplantation. His brother was mismatched donor with diversity in HLA-A and HLA-C locus. Pretransplant conditioning consisted of FluBu-4 regimen, Fludarabine $30 \mathrm{mg} / \mathrm{m}^{2}$ in days -5 to -2 , Busulfan i.v $3.2 \mathrm{mg} / \mathrm{kg}$ in days -5 to -2 . Immunosuppressive treatment was provided with cyclosporine and mycofenolate mofetil (MMF) $2 \mathrm{gr} /$ day from day +1 to day +28 and PT-CY $50 \mathrm{mg} / \mathrm{kg}$ on days +3 and +5 . His donor was primed with granulocyte colony stimulating factor $10 \mathrm{mcg} / \mathrm{kg}$ during 5 days and apheresis was completed in one procedure at Institute for transfusion medicine, Skopje, Republic of Macedonia. He received peripheral blood stem cells from his brother with $5.8 \times 10^{6} / \mathrm{kg}$ CD34+ cells in February 2019. Conditioning regimen is presented on
Figure 1. Patient experienced prolonged engraftment period complicated with lower respiratory tract infection caused with gram-negative bacterial pathogens as stenotrophomonas maltophilia, blood cultures positive on methicillin resistant staphylococcus coagulase negative and vancomycin resistant enterococcus. After aggressive parenteral antibiotic treatment, he achieved engraftment on day +22 for $\mathrm{Ne}>0.5 \times 10^{9} / \mathrm{L}$ and +16 for PIt $>20 \times 10^{9} / \mathrm{L}$. Hematopoietic recovery of the patient is presented on Figure 2. In the early posttransplant period, he had cytomegalovirus (CMV) reactivation with clinical manifestation of CMV related colitis which resolved with prolonged treatment with ganciclovir. CMV colitis was diagnosed with histology by colonoscopy and molecular testing for CMV in the material from the biopsy with polymerase chain reaction CMV DNA. Patient received ganciclovir $5 \mathrm{mg} / \mathrm{kg}$ twice daily and continued with oral valganciclovir $900 \mathrm{mg} /$ twice daily in the next 3 weeks. He had no signs of acute and chronic GVHD. Chimerism analysis were performed on $+3,+6$, $+9,+12,+15,+20$ and +24 months posttransplant and revealed high donor chimerism of $>95 \%$. Bone marrow biopsy and flowcytometry showed complete remission. After 6 months he discontinued immunosuppressive treatment with cyclosporine. Patient is now +34 months post-transplant with normal blood count $\mathrm{Hgb} 16.9 \mathrm{~g} / \mathrm{dL}$, WBC $9.6 \times 10^{9} / \mathrm{L}$, PIt $135 \times 10^{9} / \mathrm{L}$.

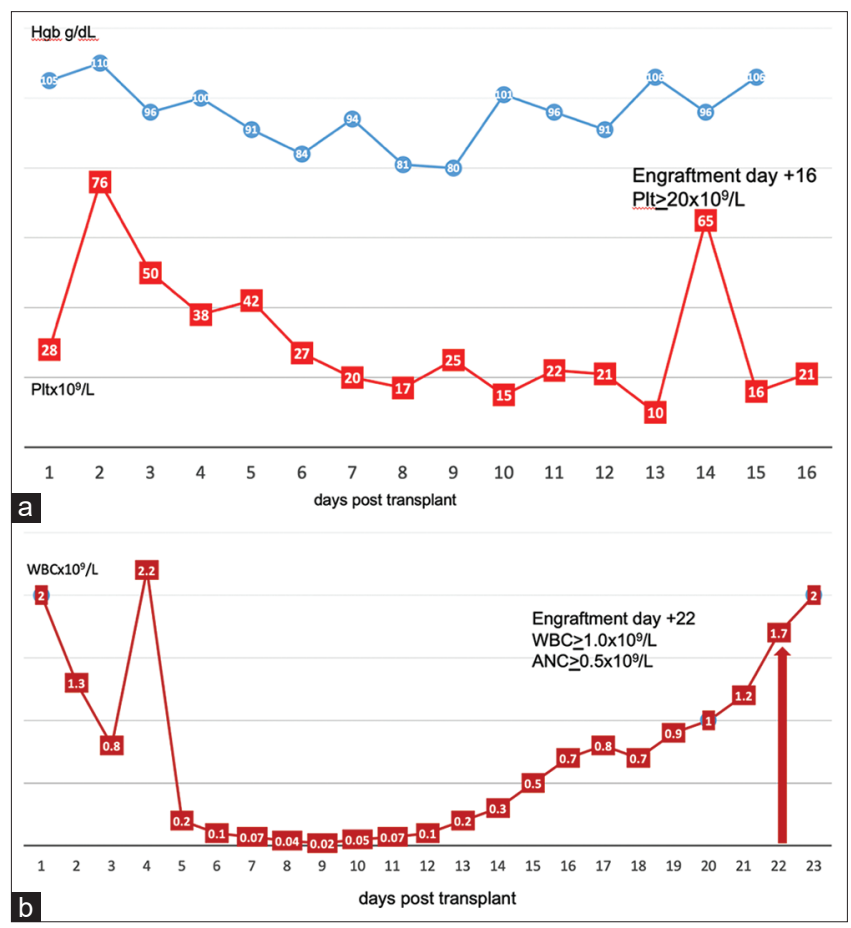

Figure 2: Hematopoietic engraftment during haploidentical stem cell transplantation. (a) Platelet and hemoglobin recovery during haploidentical stem cell transplantation. (b) Neutrofil and white blood cell recovery during haploidentical stem cell transplantation

In the late posttransplant period, he experienced decreasing in EJECTION fraction \% heart rate due to PT-CY immunosuppression and is on regular follow-up by cardiologist. Patient and donor characteristics are presented on Table 1. 
Table 1: Patient, graft and donor characteristic during haploidentical stem cell transplantation

\begin{tabular}{ll}
\hline Parameter & Value \\
\hline Disease status before transplant & MDS RAEB \\
Patient Body weight $(\mathrm{kg})$ & 75 \\
HPC Apheresis $(\mathrm{ml})$ & 330 \\
Number of apheresis procedures & 1 \\
CD34+cells/kg & $5.8 \times 10^{6} / \mathrm{kg}+22+16$ \\
Engraftment (day) & \\
WBC $>1.0 \times 10^{9} / \mathrm{L}$ & \\
PIt $>20 \times 10^{9} / \mathrm{L}$ & +22 \\
Transfusion policy & +16 \\
Er transfusions -units (filtered and irradiated) & \\
Plt concentrates & \\
Donor characteristics & 7 \\
Mismatch haploidentical & 10 \\
CMV IgG & \\
CMV IgM & \\
Blood Type & $8 / 10$ \\
Donor & Positive \\
Patient & Negative \\
Conditioning & \\
haploidentical MAC conditioning & \\
Immunosupression & A Rh(-) \\
& A Rh(+) \\
& \\
\hline MDS: Myelodysplastic syndrome, RAEB: Refractory anemia with excess blasts, CMV: Cytomegalovirus, \\
WBC: White blood cell. &
\end{tabular}

\section{Discussion}

MDS is a common hematologic disorder that typically presents with one or more cytopenias and an increased threat of converting into acute myeloid leukemia (AML). The disease course is variable, mainly conditioned by molecular alterations, marrow blast count, and cytopenia [7]. ASCT is usually limited to younger high-risk patients and rarely in very healthy older patients. As of date, this is the only curative treatment of higher-risk MDSs, with prolonged disease-free survival of $35-50 \%$. The presented case was classified as high risk patient with no comorbidities and was considered as a candidate for treatment with ASCT. The optimal timing of hematopoietic stem cell transplantation (HSCT) should take into account life expectancy without HSCT and quality of life. The timing from initial diagnosis to transplant in the presented case was 11 months. He received treatment with hypomethylating agent to prevent disease transformation into AML and donor possibilities were evaluated during treatment period. Some low-risk patients with persistent disease might live for years with supportive therapy and a relatively good quality of life. Hypomethylating agents have been reported to increase median survival and decrease transformation into leukemia in higher risk patients and should be balanced with the potential effect of transplantation [8].

The intensity of the conditioning regimen has been guided by patient's age for a longtime, meaning that young patients received myeloablative conditioning (MAC) while older or young patients with comorbidities received reduced intensity regimen reduced-intensity conditioning. Patient received MAC with FluBu-4 regimen. Post-transplant immunosuppression consisted of PT-CY, cyclosporine and MMF. Patient had prolonged engraftment period and severe infective complications. Gastrointestinal GVHD and CMV infection often simulate each other. However, distinction between GVHD and CMV infection is critical in the management of immunosuppression for transplant recipients. CMV infection during haploidentical transplantation is common complication and prompt diagnosis is necessary. Early colonoscopy after onset of symptoms and histology and molecular confirmation was essential for the patient to start early treatment with antiviral drugs. CMV colitis can mimicry intestinal GVHD and increasing immunosuppression with corticosteroids can be harmful in worsening the clinical course of infection [9].

HSCT is a curative therapy for MDS, but NRM remains a major obstacle to the success of this treatment. The risk of disease related mortality without the transplant should be balanced with the NRM. Higher risk patients have short life expectancy with chemotherapy, and will generally benefit from the HSCT. Risk for NRM should be carefully eva-uated, and relies on functional age assessment related to general performance status and comorbidities. When a patient has an indication of HSCT, a donor can be found either in the family (matched sibling or haploidentical) or in registry (MUD or mismatched unrelated) [3]. The patient didn't have HLA DNA identical family sibling and the MUD search revealed 4 available donors that were 10/10. None of them were available for donation in the time period; therefore, it was suggested to continue with mismatched family donor.

\section{Conclusion}

The use of a mismatched donor increases the risk of NRM, but there is also evidence to suggest that a haploidentical donor is a valid choice, as general outcome appears to be at least similar to MUD.

\section{References}

1. Duarte RF, Myriam L, Peter B, Grzegorz W, Chiara B, Ch C, et al. Indications for haematopoietic stem cell transplantation for haematological diseases, solid tumours and immune disorders: Current practice in Europe, 2019. Bone Marrow Transplant. 2019;54(10):1525-52. https://doi.org/10.1038/ s41409-019-0516-2

PMid:30953028

2. Robin $M$, Porcher R, Ciceri $F$, van Lint MT, Santarone $S$, Ehninger G, et al. Haploidentical transplant in patients with myelodysplastic syndrome. Blood Adv. 2017;1(22):1876-83. https://doi.org/10.1182/bloodadvances.2017007146 


\section{PMid:29296834}

3. Ciurea SO, Cao K, Fernandez-Vina M, Kongtim P, Malki MA Fuchs $\mathrm{E}$, et al. The European society for blood and marrow transplantation (EBMT) Consensus guidelines for the detection and treatment of donorspecific anti-HLA antibodies (DSA) in haploidentical hematopoietic cell transplantation. Bone Marrow Transplant. 2018;53(5):521-34. https://doi.org/10.1038/ s41409-017-0062-8

PMid:29335625

4. Xu L, Chen H, Chen J, Han M, Huang H, Lai $\mathrm{Y}$, et al. The consensus on indications, conditioning regimen, and donor selection of allogeneic hematopoietic cell transplantation for hematological diseases in china-recommendations from the Chinese society of hematology. J Hematol Oncol. 2018;11(1):33. https://doi.org/10.1186/s13045-018-0564-x

PMid:29495966

5. Bacigalupo A, Dominietto A, Ghiso A, Di Grazia C, Lamparelli T, Gualandi $F$, et al. Unmanipulated haploidentical bone marrow transplantation and post-transplant cyclophosphamide for hematologic malignanices following a myeloablative conditioning: An update. Bone Marrow Transplant. 2015;50 Suppl 2:S37-9. https://doi.org/10.1038/bmt.2015.93

\section{PMid:26039205}

6. Greenberg PL, Tuechler H, Schanz J, Sanz G, Garcia-Manero G, Solé $\mathrm{F}$, et al. Revised international prognostic scoring system for myelodysplastic syndromes. Blood. 2012;120(12):2454-65. https://doi.org/10.1182/blood-2012-03-420489 PMid:22740453

7. Ades L, Itzykson PF, Fenaux P. Myelodysplastic syndromes. Lancet. 2014;383(9936):2239-52. https://doi.org/10.1016/ S0140-6736(13)61901-7

PMid:24656536

8. Villar S, Robin M. Allogeneic stem cell transplantation for MDS. Hematology. 2021;2:545-55. https://doi.org/10.3390/ hemato2030034

9. Ljungman $\mathrm{P}$, de la Camara R, Robin C, Crocchiolo R, Einsele $\mathrm{H}$, Hill JA, et al. Guidelines for the management of cytomegalovirus infection in patients with haematological malignancies and after stem cell transplantation from the 2017 European conference on infections in leukaemia (ECIL 7). Lancet Infect Dis. 2019;19(8):e260-72. https://doi.org/10.1016/ S1473-3099(19)30107-0

PMid:31153807 